\title{
Nurses' Knowledge And Compliance With Hand Hygiene Protocols In Pediatric Health Care Settings
}

\author{
Chrisoula Dafogianni ${ }^{1}$, Olympia Paralika ${ }^{2}$, Maria Gerali $^{1,3}$, Victoria Alikari ${ }^{1,4}$ \\ ${ }^{I}$ (Nursing Department, Technological Educational Institute of Athens, Greece) \\ ${ }^{2}$ (Intensive care Unit, Alexandra Hospital of Athens, Greece) \\ ${ }^{3}(P . \& A$. Kyriakou Children's Hospital of Athens) \\ ${ }^{1,4}$ (Nursing Department, University of Peloponnese, Sparta, Greece)
}

\begin{abstract}
IntroductionHand hygiene is the basic measure against hospital infections. Nurses have the possibility to reduce the morbidity and mortality on hospital infections providing high health care quality.

Aim: To assess the level of knowledge and adherence of pediatric nurses in hand hygiene during the children's shickcare.

Methods In this descriptive study 90 nurses from Pediatric Hospitals of Athens region completed a selfadministered questionnaire from May 2013 - January 2014. Socio-demographic data of nurses were recorded. Data were analyzed with the SPSS statistical package, version 21.0.

Results $10.8 \%$ of the participants were male while 89.2 women. The mean age was 35.13 ( \pm 6.42$)$. The majority (87.8\%) of the sample applies the technique of hand washing before each nursing practice while $18.9 \%$ answered that they have not been trained in hand washing technique in hospital.

Conclusions Nursing training and retraining is required focused on programs specified in nurses' needs in order to increase adherence to hand hygiene.
\end{abstract}

Keywords: adherence, compliance, hand hygiene, nurses

\section{Introduction}

One of the main problems and challenges in hospitals, especially, in pediatric clinics, are hospital acquired infections [1]. According to the World Health Organization (WHO) 1.400 .000 people suffer from hospital acquired infections (HAI) and their complications [2]. Based on guidelines of World Health Organization (WHO) and the Centers for Disease Control (CDC), hand hygiene is the most important and easy way for hospital infection control [3, 4].Especially for children admitted to pediatric hospitals there is a high risk for hospital infection because of risk factors such as age, low levels of immunization, and lack of preventive mechanisms [5,6].Considering the increase of the prevalence of hospital infections, many children will need nursing care of health professionals [7].Nurses are an important part of the interdisciplinary team dealing with the nursing care of children. In order to reduce the morbidity and mortality of hospital infections, health care professionals should be trained in hand hygiene protocols, providing quality at each nursing intervention. The quality of patient care depends on the knowledge, skills and documented clinical practices of pediatric nurses in the workplace [8]. Therefore, more emphasis on the role of nurses in the control of hospital acquired infections should be given [9].As a result, nurses should have sufficient knowledge and skills in the field of infection control [10]. The aim of this study wasto assess the level of knowledge and adherence of pediatric nurses in hand hygiene during the pediatric patient care.

\section{Methods}

All 150 nurses in the broader area of Athens were asked to take part in this study. The nurses became from Pediatric Departments, Intensive Care Units, Emergency Departments, Surgical Pediatric Departments and Intensive Care Units of Premature Neonates in Pediatric Hospitals of Athens region. Finally, 90 nurses completed the questionnaire (response rate 60\%). A pilot study was carried out for the content validity of the scale as well as the validation (Cronbach's a). The questionnaire was constructed by experts in the field (professionals and academicians). The study was conducted from May 2013 - January 2014. Data were analyzed with the SPSS statistical package, version 21.0

\section{Data collection}

The questionnaire was developed after the study of international bibliography related to hand hygiene by health care professionals and academics. Nurses participated in the study were given a questionnaire related to sociodemographic data followed by the scale of hand-hygiene knowledge and adherence. This questionnaire contains 32 items in total. The topics of the questionnaire were divided in 2 groups: a) nurses' education on nursing protocols of hand hygiene (10 items) b) nurses' adherence on hand hygiene (22 items). The 
questionnaires were given at selected intervals throughout the day, and were returned immediately. Responses were anonymous and were returned in a closed envelope.

\section{Results}

Percentage of $10.8 \%$ of the participants were male while 89.2 women. The mean age was 35.13 $( \pm 6.42)$, (maximum: 56, minimum: 22$)$. Twenty eight participants $(31.11 \%$ ) were university graduates, 38 $(42.22 \%)$ were graduates of Technological Educational Institute and $24(26.67 \%)$ were assistant nurses. Fourteen nurses (15.56\%) were specialized nurses on Pediatric Nursing, 1 (1.11\%) on Psychiatric Counseling Nursing and $1(1.11 \%)$ on Health Administration. Percentage of $22.22 \%(n=20)$ had a master's degree in Nursing, 2.22\% $(n=2)$ had a $\mathrm{PhD}$, and $2.22 \%(\mathrm{n}=2)$ another master's degree title. The average work experience of nurses was 12.33 years $(\mathrm{SD} \pm 1.15)$. The descriptive characteristics on the responses are presented in TABLES $1 \& 2$.

Table1 Frequencies of nurses' responses on educating protocols related to hand hygiene

\begin{tabular}{|c|c|c|}
\hline ITEMS & Yes $(\%)$ & No $(\%)$ \\
\hline 1. Have you been trained in hand washing technique in hospital? & $72(80)$ & $17(18.9)$ \\
\hline $\begin{array}{l}\text { 2. Have you been trained in hand washing technique protocol with } \\
\text { liquid soap? }\end{array}$ & $68(75.6)$ & $2123.3)$ \\
\hline $\begin{array}{l}\text { 3. Have you been trained in hand washing technique protocol with } \\
\text { antiseptic soap of chlorexidine or alcohol based hand tub? }\end{array}$ & $\begin{array}{l}72 \\
(89.0)\end{array}$ & $\begin{array}{l}18 \\
(12.0)\end{array}$ \\
\hline $\begin{array}{l}\text { 4. Have you been trained in the implementation of hand washing } \\
\text { protocols to treat microbial infections }\end{array}$ & $\begin{array}{l}72 \\
(80.0)\end{array}$ & $\begin{array}{l}16 \\
(17.8)\end{array}$ \\
\hline $\begin{array}{l}\text { 5. Have you been trained in protocols for the prophylaxis of staff from } \\
\text { pediatrics infectious diseases in health care facilities? }\end{array}$ & $\begin{array}{l}51 \\
(56.7)\end{array}$ & $\begin{array}{l}39 \\
(43.3) \\
\end{array}$ \\
\hline $\begin{array}{l}\text { 6. Have you been trained in the application of the parents education } \\
\text { protocols related to hand hygiene? }\end{array}$ & $\begin{array}{l}54 \\
(60,0)\end{array}$ & $\begin{array}{l}35 \\
38.9 \\
\end{array}$ \\
\hline $\begin{array}{l}\text { 7. Do you apply parents training protocols in special handwashing techniques } \\
\text { depending on the child's illness? }\end{array}$ & $\begin{array}{l}13 \\
(14.4)\end{array}$ & $\begin{array}{l}76 \\
(84.4)\end{array}$ \\
\hline $\begin{array}{l}\text { 8. Have you record parents training protocols parents to prevent transmission } \\
\text { of nosocomial infections to their child? }\end{array}$ & $\begin{array}{l}5 \\
(5.7)\end{array}$ & $\begin{array}{l}82 \\
(94.3) \\
\end{array}$ \\
\hline $\begin{array}{l}\text { 9. Would you like to be trained on the organization and implementation of } \\
\text { handwashing technique protocols? }\end{array}$ & $\begin{array}{l}82 \\
(93.2)\end{array}$ & $\begin{array}{l}6 \\
(6.8) \\
\end{array}$ \\
\hline $\begin{array}{l}\text { 10. Is compliance of nursing and medical staff in hand hygiene evaluated by } \\
\text { the hospital system? }\end{array}$ & $\begin{array}{l}30 \\
(33.7)\end{array}$ & $\begin{array}{l}58 \\
(65.2)\end{array}$ \\
\hline
\end{tabular}

Table 2 Frequencies of nurses' responses on hand hygiene compliance during nursing care of children

\begin{tabular}{|c|c|c|}
\hline ITEMS & Yes $(\%)$ & No $(\%)$ \\
\hline $\begin{array}{l}\text { 1. Do you know what you should do before applying venipuncture to the child in } \\
\text { clinic work environment? }\end{array}$ & $55(61.1)$ & $35(38.9)$ \\
\hline $\begin{array}{l}\text { 2. Do you apply the technique of hand washing and use sterile gloves before } \\
\text { venipuncture? }\end{array}$ & $23(25.6)$ & $67(74.4)$ \\
\hline Do you apply alcohol based hand rub before venipuncture? & $52(57.8)$ & $38(42.2)$ \\
\hline Do you apply the technique of hand washing before the bronchial aspiration? & $86(95.6)$ & $4(4.4)$ \\
\hline Do you wash your hands and use sterile gloves before the bronchial aspiration? & $33(36.7)$ & $57(63.3)$ \\
\hline Do you apply the alcohol based hand rub before the bronchial aspiration? & $80(88.9)$ & $10(11.1)$ \\
\hline Do you apply the nursing care protocol of hand washing technique with liquid soap? & $79(87.8)$ & $11(12.2)$ \\
\hline $\begin{array}{l}\text { 8. Do you apply nursing care protocol of hand washing technique before every type of } \\
\text { practice? }\end{array}$ & $79(87.8)$ & $10(11.1)$ \\
\hline $\begin{array}{l}\text { 9. Do you apply the hand washing technique protocol with antiseptic soap of } \\
\text { chlorexidine or alcohol based hand rub? }\end{array}$ & $76(84.4)$ & 13(14.4) \\
\hline 10. Do you apply the hand washing technique before the placement of nasogastric tube? & $88(98.9)$ & $1(1.1)$ \\
\hline 11. Do you apply alcohol based hand rub before the placement of nasogastric tube? & $78(86.7)$ & $12(13.3)$ \\
\hline $\begin{array}{l}\text { 12. Do you wash your hands and apply sterile gloves before the placement of nasogastric } \\
\text { tube? }\end{array}$ & $37(4.1)$ & $53(58.9)$ \\
\hline 13. Do you apply the hand washing technique before the placement of urine catheter? & $88(97.8)$ & $2(2.2)$ \\
\hline $\begin{array}{l}\text { 14. Do you wash your hands and apply sterile gloves before the placement of urine } \\
\text { catheter? }\end{array}$ & $77(85.6)$ & 13(14.4) \\
\hline 15. Do you apply alcohol based hand rub before the placement of urine catheter? & $57(63.3)$ & $33(36.7)$ \\
\hline 16. Do you apply the hand washing technique before the administration of medications? & $89(97.8)$ & $1(2.2)$ \\
\hline 17. Do you apply alcohol based hand rub before the administration of medications? & $78(86.7)$ & $12(13.3)$ \\
\hline $\begin{array}{l}\text { 18. Do you apply the hand washing technique before the administration of intravenous } \\
\text { drugs? }\end{array}$ & $87(96.7)$ & $1(1.1)$ \\
\hline $\begin{array}{l}\text { 19. Do you wash your hands and apply sterile gloves before the administration of } \\
\text { intravenous drugs? }\end{array}$ & $73(81.1)$ & $17(18.9)$ \\
\hline 20. Do you apply alcohol based hand rub before the administration of intravenous drugs? & $77(85.6)$ & $13(14.4)$ \\
\hline $\begin{array}{l}\text { 21. Do you apply the hand washing technique before every nursing practice on } \\
\text { immunocompromised child? }\end{array}$ & $89(97.8)$ & $1(2.2)$ \\
\hline $\begin{array}{l}\text { 22. Do you apply the technique of hand washing and use the necessary equipment, (face } \\
\text { mask, hat, blouse and gloves) before any intervention? }\end{array}$ & $71(78.9)$ & $18(20.0)$ \\
\hline
\end{tabular}




\section{Discussion}

The increasing prevalence of hospital infections leads to the urgent need of responding of health professionals to the increasingly need of taking care of children who are hospitalized $[3,4]$.Especially for children who are hospitalized in intensive care units and in special departments, such as oncology, nurses are required to have specialized knowledge and skills in accordance with the guidelines [11]. The latest knowledge of nurses in the implementation of daily clinical practice is essential for the safety of the application of nursing procedures [12].In this study, only $60 \%$ of the sample of nurses responded to the questions of knowledge and skills of nurses hand washing during the nursing care of pediatric patients. Even a percent of $80.0 \%$ of the sample declared to have been trained in hospital for hand washing technique while $17.8 \%$ no, it was found that only one third did not own the acceptable level of knowledge of the technique of hand washing.

Regarding the application of theoretical knowledge on the technique of hand washing before each type of practice, $87.8 \%$ of the sample answered yes while $12.2 \%$ answered no. It was found, therefore, that the majority of the sample applies the technique of hand washing before each nursing practice. This means that nurses have an acceptable level of knowledge and skills, which, at the same time, apply it in the nursing care of children.The largest (89\%) proportion of the sample has been trained in the use of antiseptic (alcoholic) solution, which is one of the necessary steps for hand hygiene.According to the answers of respondents $33,7 \%$ answered that compliance of nurses is evaluated by the hospital while $65.2 \%$ answered negatively. It is worth noted, therefore, the incomplete contribution hospital system especially on an important issue such as hospital infections which are the result of the lack of proper hand hygiene. We conclude, therefore, that the absence of competent bodies leads health professionals to work according to their conscience and their education.

Therefore, based on the above information, nurses have the knowledge and skills for hand washing during the nursing care of children. Also, the majority of nurses $(93.2 \%)$ wish to be trained in organizational protocols for hand washing providing properly their knowledge and skills.

Regarding the use of sterile gloves before the inserting of urinary catheter or nasogastric catheter, $85.6 \%$ and $86.7 \%$ respectively answered correctly, while $14.4 \%$ and $13.3 \%$ answered wrong. So, we observe that the majority of nurses have knowledge of prevention of infections during the urinary catheter placement and nasogastric catheter. Also, the largest percentage $(81.8 \%)$ of respondents answered correctly for hand washing and use sterile gloves before administering intravenous drugs. The same is true for the technique of suction. The largest percentage of respondents answered wrong, that is $63.3 \%$ and only $36.7 \%$ answered correctly. Also, $78.9 \%$ of the sample answered correctly in implementing of the necessary measures before entering the chamber where the immunocompromised child is hospitalized while $20 \%$ answered wrong. Especially in the case of the hospitalized immunocompromised child, the percentage of $20 \%$ of the sample should be taken seriously because it is an important indicator of risk factors of transmission of health care acquired infections.

Compliance staff in accordance with the guidelines of hand hygiene is necessary in order to reduce the transmission of pathogenic microorganisms, as it is demonstrated in a plethora of studies [13-16].Ignaz Semmelweis had first found the need for hand washing resulting to the reduction of mortality from $18 \%$ to the $12.24 \%$ [17].Hand washing is, also, required before any type of practice, reducing the transfer of pathogenic microorganisms even during "clean" activities such as assessing vital signs, according to past studies. ${ }^{18}$ Casewell\& Phillips (1977) showed that nurses could contaminate their hands, with 100 to 1000 CFU of Klebsiella spp. during "clean" activities if they did not apply the guidelines of the World Health Organization [19].Also, during the neonatal care, the use of gloves did not protect the hands of workers. Instead, both hand washing and use of gloves reduced the average growth of bacteria on the hands of workers [20].

Training in the use of antiseptic solution and applying prior to any type of nursing practice significantly reduced the hand contamination from transient microorganisms according to Trick et al[21] and Mc Neil [22]. The use of alcoholic solution before and after each type of nursing practice according to the guidelines of Centers of Disease Control has reduced pathogens on the hands, according to the above researchers. In this study, the level of education and alcoholic solution implementation is quite high. Although these data, our country holds a leading position in Europe for hospital infections [23].Generally, according to the results of this study, education is incomplete as nurses do not have the same knowledge rate for each nursing practice while the evaluation of staff by the competent bodies is equally incomplete. Thus, there is an urgent need to organize education programs to improve the knowledge and skills of nurses for hand washing on the nursing care of children.Completing this study we consider that nurses have a responsibility to educate children and their relatives using the latest guidelines for hand washing in hospital. The recorded percentage of parents training protocols in this study is very small $(5.7 \%)$. Therefore, necessary systematization of nursing education is required in order to organize programs specified in nurses' needs after investigation of the pre-existing level of knowledge. In addition, certified instructors on hand hygiene should be chosen, who also have experience in evidence based clinical practice. 


\section{Limitations}

This study was conducted during the shift. So, environmental factors such as interference from other colleagues or patients should be taken seriously into consideration.

\section{Conclusions}

Competent bodies should intensify their efforts for the health promotion of children by implementing continuing education programs, giving the opportunity for all nurses to watch thus improving constantly their knowledge. Furthermore, the evaluation of the nurses from the hospital management forces them to adhere and apply their knowledge in clinical practice.

\section{References}

[1] EN. Berezin, F. Solorzano, and Latin America Working Group on Bacterial Resistance. Gram-negative infections in pediatric and neonatal intensive care units of Latin America,Journal of Infection in Developing Countries, 13 (8), 2014, 942-953

[2] World Health Organization. Improved hand hygiene to prevent health care associated infections. Available from: http:// www. who. int/gpsc/tools/faqs/ evidence_hand_hygiene/en/2014

[3] VS. Sharma, S. Dutta, N. Taneja, and A. Narang. Comparing hand hygiene measures in a neonatal ICU: a randomized crossover trial, Indian Pediatrics, 50(10), 2013,917-921.

[4] HY. Park, SK.Kim, YJ.Lim, SH.Kwak,MJ. Hong, HM. Mun, SY. Park, HJ. Kim, HR. Choi, JS. Jeong, MN. Kim, and SH. Choi. Assessment of the appropriateness of hand surface coverage for health care workers according to World Health Organization hand hygiene guidelines. American Journal of Infection Control, 42(5), 2014, 559-561.

[5] M.Asadollahi, MA. Bostanabad, M.Jebraili, M. Mahallei, AS. Rasooli, and M Abdolalipour,Nurses’ Knowledge Regarding Hand Hygiene and Its Individual and Organizational Predictors, Journal of Caring Sciences, 4 (1), 2015,45-53.

[6] R. Nazari,AM Haji, M. Dadashzade, and P.Asgari. Study of hand hygiene behavior among nurses in Critical Care Units. Iranian Journal of Critical Care Nursing, 4 (2), 2011, 95-98

[7] JM. Boyce, D. Pittet, Healthcare Infection Control Practices Advisory Committee; HICPAC/SHEA/APIC/IDSA Hand Hygiene Task Force.Guideline for Hand Hygiene in Health-Care Settings. Recommendations of the Healthcare Infection Control Practices Advisory Committee and the HICPAC/SHEA/APIC/IDSA Hand Hygiene Task Force. Society for Healthcare Epidemiology of America/Association for Professionals in Infection Control/Infectious Diseases Society of America.MMWR Recomm Rep. 51(RR16), 2002,1-45

[8] YS Galal, JR Labib, and WA Abouelhamd. Impact of an infection-control program on nurses' knowledge and attitude in pediatric intensive care units at Cairo University hospitals.Journal of Egyptian Public Health Association, 89(1), 2014, 22-28.

[9] M. Asadollahi, BM. Arshadi, M. Jebraili , M. Mahallei, RA Seyyed, and M Abdolalipour, Nurses’ Knowledge Regarding Hand Hygiene and Its Individual and Organizational Predictors, Journal of Caring Sciences, 4 (1), 2015, 45-53.

[10] F. Joukar, and EZ. Taherri, Nursing student and staff knowledge about nosocomial infection, Iranian Journal of Infectious Diseases, 12 (37), 2007, 83-86.

[11] A. Toska, and M. Geitona, Antibiotic resistance and irrational prescribing in paediatric clinics in Greece, British Journal of Nursing, 24(1), 2015, 28-33.

[12] G. Cicolini, V. Simonetti, D. Comparcini, S. Labeau, S. Blot, G. Pelusi and P Di Giovanni, Nurses' knowledge of evidence-based guidelines on the prevention of peripheral venous catheter-related infections: a multicentre survey, Journal of Clinical Nursing.23(17-18), 2014 2578-2588

[13] WI. Liu, SY. Liang, SF. Wu, andYH, Chuang, Hand hygiene compliance among the nursing staff in freestanding nursing homes in Taiwan: a preliminary study, International Journal of Nursing Practice, 20 (1), 2014,46-52

[14] A. Ghorbani, L. Sadeghi, A. Shahrokhi, A. Mohammadpour, M Addo, and E Khodadadi, Hand hygiene compliance before and after wearing gloves among intensive care unit nurses in Iran, American Journal of Infection Control,2016,doi: 10.1016/j.ajic.2016.05.004.

[15] LJ. Conway, Challenges in implementing electronic hand hygiene monitoring systems, American Journal of Infection Control, 2016, doi: 10.1016/j.ajic.2015.11.031

[16] ASC Belela-Anacleto, DM Kusahara,MA Peterlini, and M Pedreira, Behavioral determinants of hand hygiene compliance in a pediatric intensive care unit from Brazil, Intensive Care Medicine Experimental. 2015;3(Suppl 1):A721. doi:10.1186/2197-425X-3S1-A721.

[17] P. Rangappa,Ignaz Semmelweis--Hand washing Pioneer. The Journal of the association of the physicians of India, 63(3), 2015, 567.

[18] R. Shah, DV. Patel, K.Shah, A. Phatak, and S.Nimbalkar, Video Surveillance audit of hand-washing practices in a neonatal intensive care unit, Indian Pediatrics, 52 (5),2015,409-411

[19] M. Casewell, and I.Phillips, Hands as route of transmission for Klebsiella species,British Medical Journal, 2 (6098), 1977, 13151317.

[20] DA. Kaufman, A. Blackman, MR. Conaway, RA. Sinkin,Nonsterile glove use in addition to hand hygiene to prevent late-onset infection in preterm infants: randomized clinical trial, JAMA Pediatrics, 168 (10), 2014,909-916.

[21] WE. Trick, MO. Vernon, RA. Hayes, C. Nathan, T.W. Rice, BJ. Peterson, J. Segreti, SF. Welbel, SL. Solomon,and RA. Weinstein,Impact of Ring Wearing on Hand Contamination and Comparison of Hand Hygiene Agents in a Hospital, Clinical Infectious Diseases, 36, 2003, 1383-90

[22] SA. McNeil,CL. Foster, SA. Hedderwick, and CA. Kauffman, Effect of hand cleansing with antimicrobial soap or alcohol-based gel on microbial colonization of artificial fingernails worn by health care workers. Clinical Infectious Diseases, 32, 2001, 32:367-372.

[23] G. Poulakou, I. Katsarolis, I.Matthaiopoulou,S. Tsiodras, S.Kanavaki,D. Hatzaki, E. Roilides, D. Sofianou, I. Kavaliotis, A. Kansouzidou, DA. Kafetzis, I. Paraskakis, M. Foustoukou, GL. Daikos, V.Syriopoulou, A. Pangalis,S. Leveidiotou , H. Giamarellou;Hellenic Study Group for the Susceptibility of Streptococcus pneumoniae, on behalf of the Hellenic Study Group for the Susceptibility of Streptococcus pneumonia,International Journal of Antimicrobial Agents,30 (1),2007,87-92. 